\title{
Drilling thick fabric woven CFRP laminates with double point angle drills
}

\author{
Yiğit Karpat ${ }^{\mathrm{a}, *}$, Burak Değer ${ }^{\mathrm{b}}$, Onur Bahtiyar ${ }^{\mathrm{b}}$ \\ a Bilkent University, Department of Industrial Engineering, Ankara 06800, Turkey \\ ${ }^{\mathrm{b}}$ Turkish Aerospace Industries Inc., Ankara 06980, Turkey
}

\section{A R T I C L E I N F O}

\section{Article history:}

Received 18 February 2012

Received in revised form 22 April 2012

Accepted 25 May 2012

Available online 2 June 2012

Keywords:

Machining

Drilling

Carbon fiber reinforced plastics

Diamond coated carbide

\begin{abstract}
A B S T R A C T
Carbon fiber reinforced plastics (CFRPs) have many desirable properties, including high strength-toweight ratio, high stiffness-to-weight ratio, high corrosion resistance, and low thermal expansion. These properties make CFRP suitable for use in structural components for aerospace applications. Drilling is the most common machining process applied to CFRP laminates, and it is difficult due to the extremely abrasive nature of the carbon fibers and low thermal conductivity of CFRP. It is a challenge for manufacturers to drill CFRP materials without causing any delamination on the work part while also considering the economics of the process. The subject of this study is the drilling of fabric woven type CFRP laminates which are known to be more resistant to delamination than unidirectional type CFRP laminates. The objective of this study is to investigate the influence of double point angle drill geometry on drilling performance through an experimental approach. An uncoated carbide and two diamond coated carbide drills with different drill tip angles are employed in drilling experiments of aerospace quality thick fabric woven CFRP laminates. Force and torque measurements are used to investigate appropriate drilling conditions based on drill geometry and ideal drilling parameters are determined. Tool life tests of the drills were conducted and the condition of the diamond coating is examined as a function of drilling operational parameters. High feed rate drilling experiments are observed to be favorable in terms of drill wear. Feed is observed to be more important than speed, and the upper limit of feed is dictated by the drill design and the rigidity of the machine drill. Hole diameter variation due to drill wear is monitored to determine drill life. At high feeds, hole diameter tolerance is observed to be more critical than hole exit delamination during drilling of fabric woven CFRP laminates.
\end{abstract}

(C) 2012 Elsevier B.V. All rights reserved.

\section{Introduction}

Lightweight, durable, and corrosion resistant, carbon fiber reinforced plastics (CFRPs) have been increasingly used in the aerospace industry to build more reliable and fuel efficient aircrafts. Currently, fuel cost is calculated to be around 32\% of the airlines' operating cost, whereas it was 14\% in 2003 (IATA, 2012). Airlines have reacted to this financial pressure by replacing older aircrafts with a new generation of aircrafts that are more fuel efficient. This efficiency in part comes from increased use of sophisticated materials.

Composite parts are manufactured near-net shape; however, additional machining operations such as drilling and milling may be required to meet final design specifications. The subject of this study is drilling, which is the most common machining process applied to composite laminates. While drilling CFRP laminates, cutting drills rapidly wear out due to the highly abrasive nature of the carbon fibers and the low thermal conductivity of CFRP. The heat generated during drilling is localized at the cutting drill edge, thereby causing rapid drill wear. Delamination is a crucial problem

\footnotetext{
* Corresponding author. Tel.: +90 312290 2263; fax: +90 3122664054

E-mail address: ykarpat@bilkent.edu.tr (Y. Karpat).
}

when drilling CFRP laminates, since it decreases the load carrying capability of the composites by separating the plies. Delamination is closely related to wear and controlled during machining operations. Dimensional integrity of the holes and hole surface quality are also important considerations.

In the literature, studies on machining CFRP are limited compared to studies of metals; however, due to increasing usage of this material in the aerospace industry the number of studies on machining CFRP laminates has significantly increased in recent years. Koplev et al. (1983) reported the significance of fiber direction on the chip formation mechanism and observed that brittle fracture is the main cause of chip formation. Caprino et al. (1998) investigated machining forces during orthogonal machining of CFRPs. They observed that forces are mainly due to the contact between work material and the flank face of the drill. Hocheng and Dharan (1990) and Zhang et al. (2001) developed analytical cutting models for the orthogonal machining of CFRP laminates to predict cutting forces. They used these models to predict the critical thrust force beyond which delamination occurs.

Experimental studies have been pursued to better understand the relationships between process inputs, such as machining parameters and drill geometry, and process outputs such as cutting forces, torque, tool wear and drilled hole quality. In an extensive 


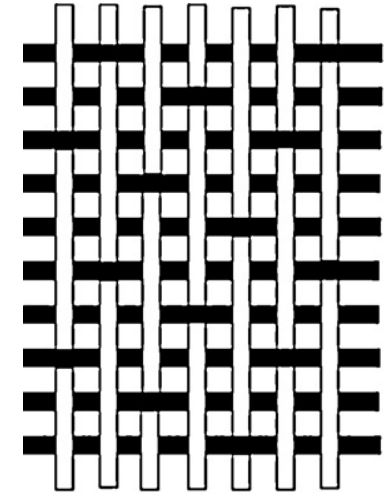

(a)

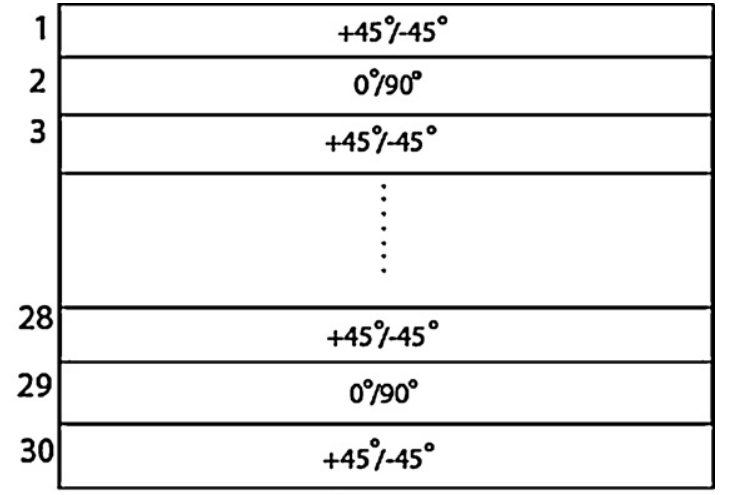

(b)

Fig. 1. (a) Five harness satin weave CFRP and (b) CFRP laminate composition.

experimental study, Chen (1997) conducted tests to reveal the relationship between machining parameters and delamination. A linear relationship was observed between thrust force and delamination when drilling unidirectional CFRP composite laminates. Multidirectional CFRP laminates are found to be more resistant to delamination than unidirectional laminates. It was observed that delamination increases with increasing flank wear. Tsao and Hocheng (2005) and Hocheng and Tsao (2005) reported the positive influence of using backup plates on delamination. It increases the critical thrust force value, hence allowing drilling at higher feeds. In an effort to improve drill performance, Piquet et al. (2000) analyzed the effects of drill geometry on hole quality. They reported that hole quality can be improved by applying a variable feed rate while machining. Dharan and Won (2000) proposed an intelligent control scheme based on an experimental model of the thrust force and torque as a function of cutting parameters. Shyha et al. (2009) investigated the effect of drill geometry and operating parameters when drilling small diameter holes with a robot manipulator. They found that drill geometry and feed rate are the two main factors affecting drill life. They found that an uncoated carbide stepped drill with $140^{\circ}$ point angle yielded the best drill life performance. Rawat and Attia (2009) utilized the "machinability maps" approach to select cutting conditions when drilling fabric woven composites. In their approach, delamination level, hole diameter error, hole circularity error, and surface roughness inside the hole were all considered as process outputs dependent on spindle speed and feed rate. They concluded that high cutting speeds reduce the thrust force due to thermal softening. Faraz et al. (2009) studied the wear behavior of uncoated and coated carbide drills while machining fabric woven CFRP composite laminates under dry drilling conditions. They showed that when worn out, the cutting edge assumes a rounded shape that hinders its ability to cut the material effectively. They also observed a linear relationship between edge rounding and cutting forces. Iliescu et al. (2010) proposed a wear model based on the thrust force and machining parameters for drilling CFRP. They concluded that while carbide drills represent wear behavior according to power law, diamond coated drills exhibit linear behavior at the beginning but power law toward the end of drill life. They recommend using diamond coated drills having $125-130^{\circ}$ point angle, with optimum cutting speed $170 \mathrm{~m} / \mathrm{min}$ and feed $0.05 \mathrm{~mm} / \mathrm{rev}$. Karpat et al. (2010) presented experimental data on the wear behavior of diamond coated carbide drills, showing the fracturing of diamond coating and edge rounding of the carbide substrate. Lazar and Xirouchakis (2011) investigated the cutting forces based on drill geometries and cutting parameters using a backing plate; they calculated force distributions along the cutting edges at low feeds and also concluded that feed and drill geometry are the most important parameters. Literature reviews on machining composites given by Teti (2002) and Abrao et al. (2007) emphasize the importance of developing better drill geometries and machining strategies.

In this study, uncoated carbide and diamond coated carbide drills having double point angle geometries are tested during drilling of fabric woven type CFRP laminates under practical conditions. Experimental tests were performed on aerospace quality thick CFRP material using a state of the art machine tool specifically designed for composite machining. An experimental analysis has been conducted to investigate the influence of cutting conditions and drill geometry on drilling forces and tool wear.

\section{Experimentation}

Experimental studies were conducted on a Dörries Scharmann Technologies 5-axis precision machining center with maximum $24,000 \mathrm{rpm}$ rotational speed. Fabric woven CFRP laminates have a total of 30 layers, composed of $0^{\circ} / 90^{\circ}$ (14 layers) and $\pm 45^{\circ}$ (16 layers) fiber orientations as shown in Fig. 1. The CFRP plates were ultrasonically inspected for faults before experimentation. The physical and mechanical properties of the CFRP laminate used in this study are given in Table 1 .

The CFRP plate had a square shape with edge dimensions of $920 \mathrm{~mm}$ and thickness of $10 \mathrm{~mm}$. The distance between hole centers is taken as equal to two times the hole diameter. An aluminum backing plate having $8 \mathrm{~mm}$ diameter holes was used. All experiments were conducted under wet drilling conditions in order to prevent carbon dust. The cutting fluid is water soluble oil (Fuchs Ecocool). During drilling experiments the thrust force and torque were measured by a Kistler 9123 rotating dynamometer and its charge amplifier. The cutting force data (torque $T$ and forces in three directions $F_{x}, F_{y}$, and $F_{z}$ ) were collected (sampling rate of $25 \mathrm{kHz}$ ) through a data acquisition system and processed on a personal computer. The experimental setup is shown in Fig. 2.

Uncoated and diamond coated carbide drills were used in the experiments. Drills employed in this study have twist drill geometry with double point angles. They are obtained from the same manufacturer. Table 2 shows experimental conditions used in drilling force analysis and drill tip angles. Drill tip angles are measured with an optical tool measurement device (Zoller Venturion 450/6). UC and DCC-II drills have the same geometry. DCC-I and DCC-II are diamond coated carbide drills with different tip angles and different primary (OA) and secondary ( $\mathrm{AB}$ ) cutting edge lengths.

The geometry of the double point angle drill is shown in Fig. 3(a) and a comparison of tool tip geometries are shown in Fig. 3(b). The helix angle $(\theta)$, the rake angle $(\rho)$, and the clearance angle $(\gamma)$ of the drills are $30^{\circ}, 7^{\circ}, 11^{\circ}$, respectively. A region on the drill near its 
Table 1

Material properties of CFRP laminates.

\begin{tabular}{|c|c|c|c|c|c|}
\hline Material & Fiber volume(\%, v/v) & Strength (MPa) & Modulus (GPa) & Density $\left(\mathrm{g} / \mathrm{cm}^{3}\right)$ & Cured ply thickness (mm) \\
\hline Epoxy impregnated graphite fabric/5-harness satin ${ }^{a}$ & 50 & 520 & 52 & 1.485 & 0.33 \\
\hline
\end{tabular}

a Mechanical properties of the laminate are valid for both warp and fill directions at $23^{\circ} \mathrm{C}$.

Table 2

Range of cutting conditions used in drilling force analysis on fabric woven CFRP.

\begin{tabular}{|c|c|c|c|c|c|}
\hline Acronym & Tool coating & Diameter $(\mathrm{mm})$ & Drill tip angles $(2 \alpha, 2 \beta)$ & Feed $(\mu \mathrm{m} / \mathrm{rev})$ & Rotational speed (rpm) \\
\hline UC & Uncoated carbide & 6.35 & $140-60^{\circ}$ & $40,60,100$ & $5000,7500,10,000$ \\
\hline DCC-I & Diamond coated carbide & 6.91 & $130-60^{\circ}$ & $40,60,100$ & $5000,7500,10,000$ \\
\hline DCC-II & Diamond coated carbide & 6.38 & $140-60^{\circ}$ & $40,60,100,150$ & $5000,7500,10,000$ \\
\hline
\end{tabular}

chisel edge ( $\mathrm{OA}^{\prime}$ as shown in Fig. 3(b)) is ground in order to improve drilling performance at the tip of the drill. Fig. 3(a) also shows the differential cutting $\left(\mathrm{d} F_{\mathrm{c}}\right)$, thrust $\left(\mathrm{d} F_{\mathrm{z}}\right)$ and tangential $\left(\mathrm{d} F_{\mathrm{t}}\right)$ forces acting on the drill. Multiplying the differential cutting force and the distance from the center gives the differential torque. Adding together all differential thrust forces and torques along the cutting edges yields total torque and thrust force during drilling.

\section{Experimental investigation of thrust forces and torques}

A fundamental step in understanding the drilling mechanics of CFRP material is the investigation of cutting forces. As

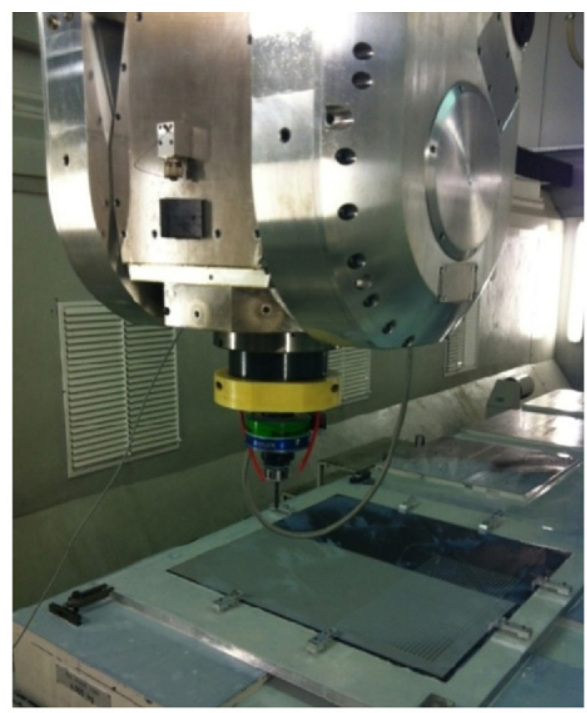

(a)

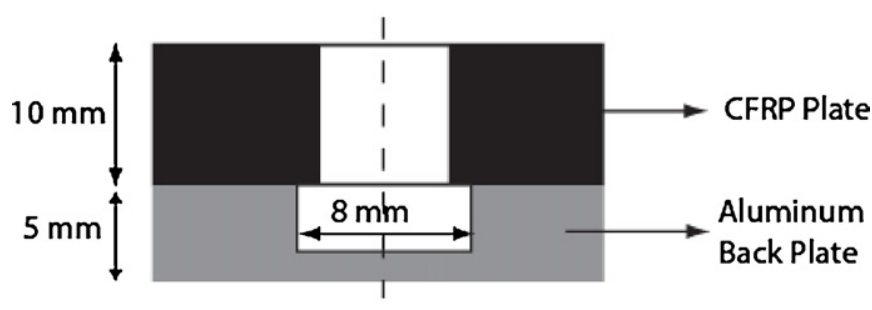

(b)

Fig. 2. Experimental test setup. (a) Fabric woven CFRP plate and (b) CFRP plate and aluminum backing plate assembly.
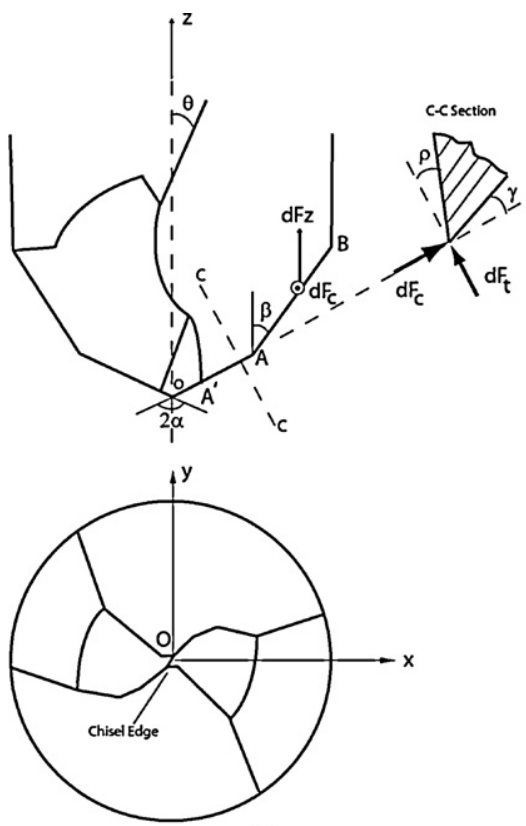

(a)

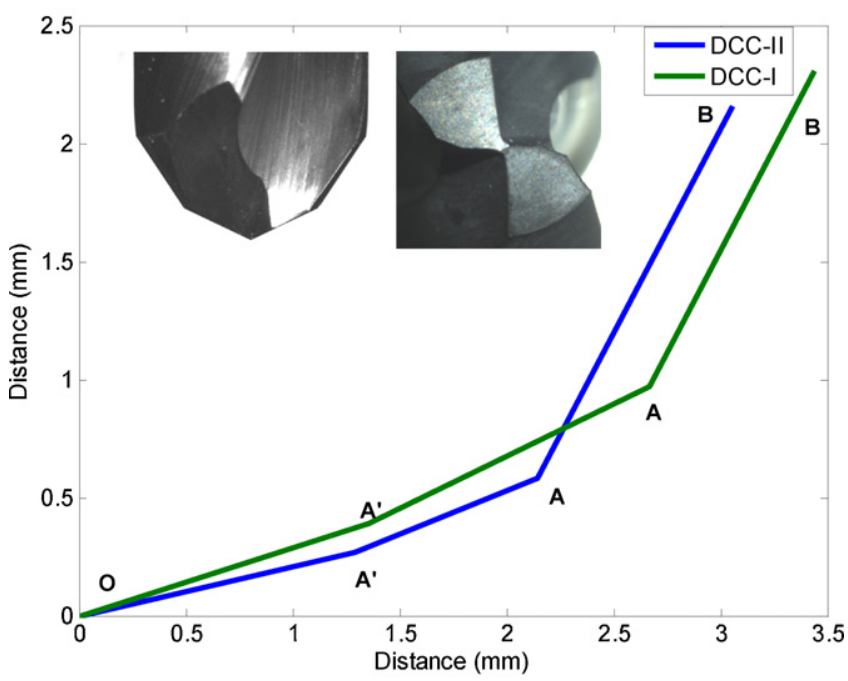

(b)

Fig. 3. (a) Double point angle drill geometry and (b) profiles of the double point angle drills. 


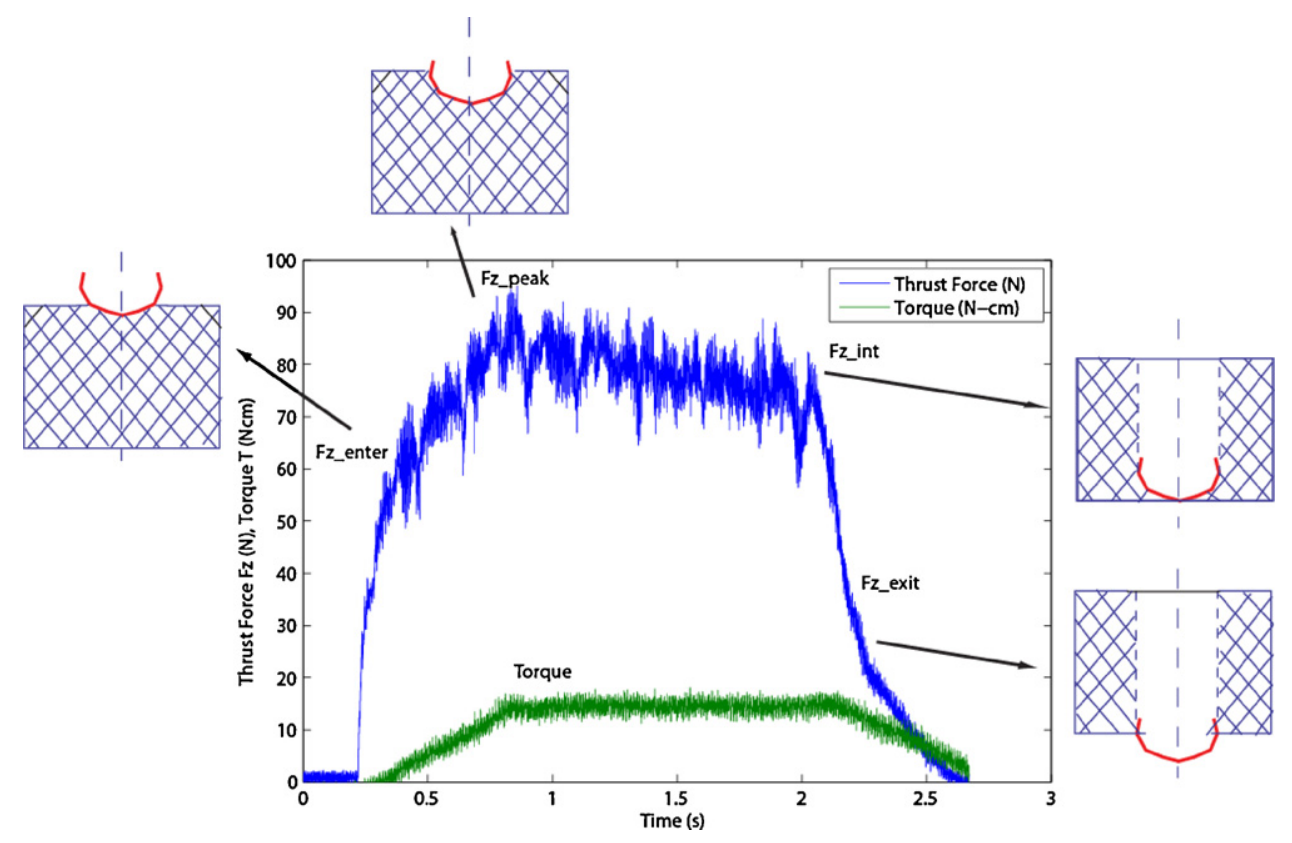

Fig. 4. Thrust force $(\mathrm{N})$ and torque $(\mathrm{N} \mathrm{cm})$ measurements during drilling with double point drill geometry and characteristic thrust force locations.

mentioned in Section 1, the forces during drilling have been the subject of many studies in the literature. Cutting force measurements have been used online and/or offline to monitor drill condition. The magnitude and development of drilling forces are dependent on mechanical properties of the composite material, operational drilling parameters (rotational speed and feed), drill geometry, and drill material/coating. Fig. 4 shows a typical thrust force and torque measurement, where drill geometry dependent characteristic thrust force and torque locations are indicated.

Due to double point angle, the entrance region has two different slopes where the entry $(\mathrm{OA})$ value is denoted as $F_{z \text {-enter }}$ and the peak $(\mathrm{OB})$ value is denoted as $F_{z \text {-peak }}$. Torque value reaches its peak as soon as the drill fully engages (OB) with the material. The thrust force values measured in the entry region indicate the influence of drill tip angles on thrust forces. A sudden drop in thrust forces is observed just after the drill tip leaves the material. Since the outer cutting edge, which is carrying the torque, would still be in contact with the material, drop in torque follows thrust force after a short delay. Similar to the entry region, two different slopes are also observed on the exit region. The thrust force value immediately before the drill tip leaves the material is named as $F_{z \text {-int. The thrust }}$ force at the end of the second slope is named as $F_{z \text {-exit. }}$. The amount of thrust forces $F_{z \text {-int }}$ and $F_{z \text {-exit }}$ are important since they indicate the magnitude of the force with which the drill pushes the bottom layers of the laminate. The characteristic thrust force and torque locations can be identified using geometrical measurements of the drill, drilling feed rate, and time history of the thrust forces and torques. It must be noted that the location of the force points is related to the drill angles and cutting edge lengths. For a given drill tip angle, a larger primary cutting edge moves the location of the peak force toward the left on the time axis and upwards on the thrust force axis. The decrease between $F_{z \text {-peak }}$ and $F_{z \text {-int }}$ is related both to the thickness of the laminate and the feed value.

Fig. 5 represents experimental force and torque measurements when drilling with uncoated carbide drills as a function of feed under constant rotational speed of $5000 \mathrm{rpm}$. A linear relationship between feed and thrust forces and torques exists within the experimental range.

Fig. 6 represents the influence of cutting speed and feed on thrust forces and torque when drilling with DCC-I drill. In Fig. 6(a), the linear relationship between thrust forces and feed is shown for three different rotational speeds. Fig. 6(b) shows torque measurements as a function of feed and speed.

Fig. 7(a) and (b) shows the same obervations for DCC-II drill. It can be concluded that the influence of cutting speed is not significant on the thrust forces and torques for diamond coated carbide drills. Higher thrust forces and torques are measured with DCC-II which has a larger tip angle.

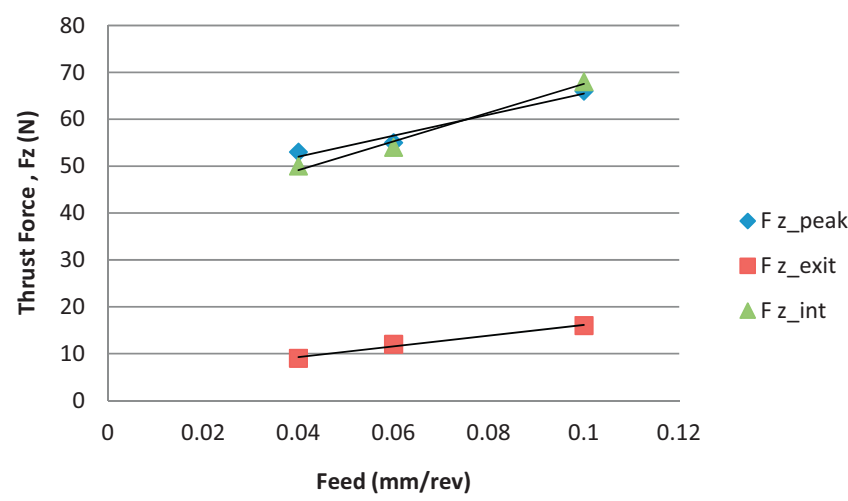

(a)

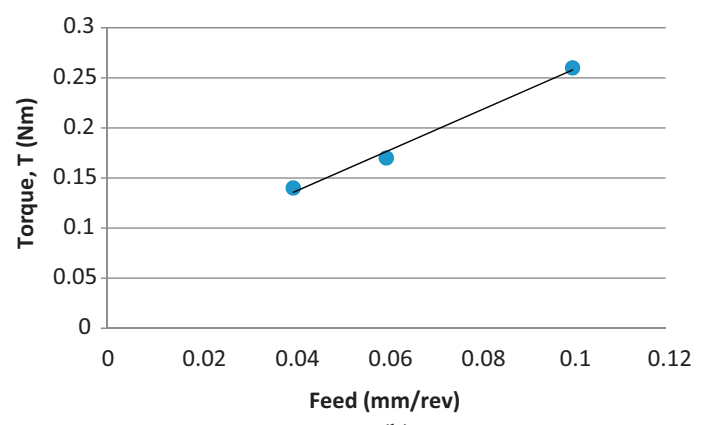

(b)

Fig. 5. Comparison of thrust force and torque measurements at three different feed levels for uncoated carbide drill. 


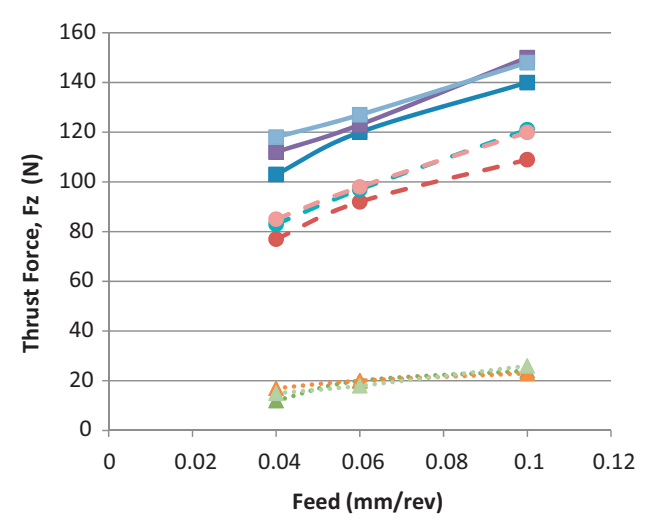

(a)

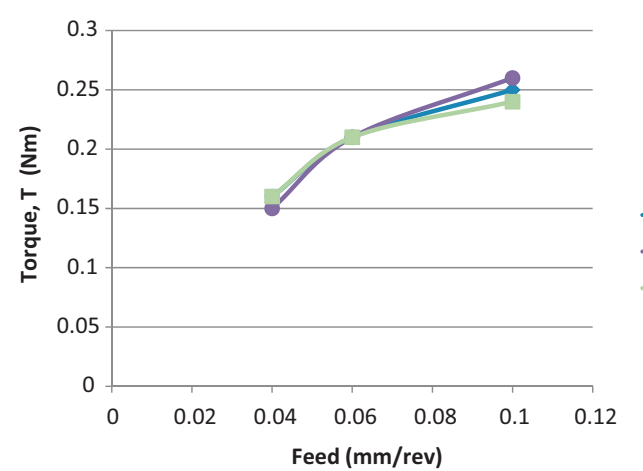

(b)

Fig. 6. Thrust force (a) and torque (b) measurements as a function of feed and speed for DCC-I.

Fig. 8 shows the comparison of thrust forces for each drilling drill examined in this study. Uncoated carbide and DCC-II have the same geometry, but the differences in thrust forces are quite large due to thick diamond coating and its rounding effect on the cutting edges. DCC-I, with a smaller tip point angle, yielded lower thrust forces than DCC-II even though it has an $8 \%$ larger drill diameter. The lowest exit thrust forces are recorded with DCC-I which has
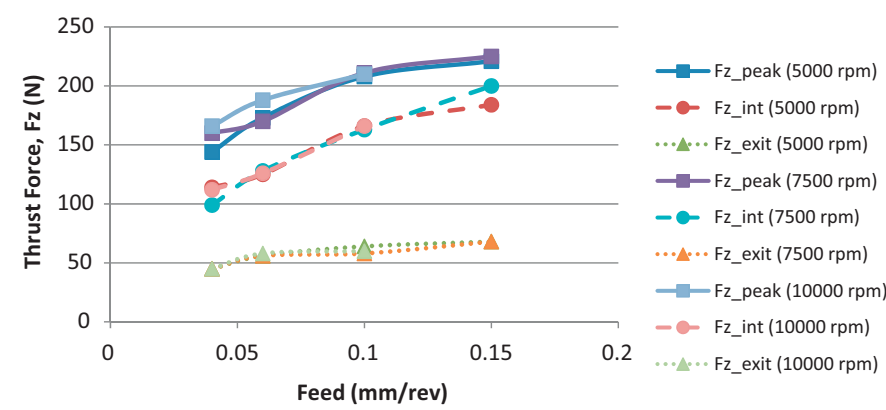

(a)

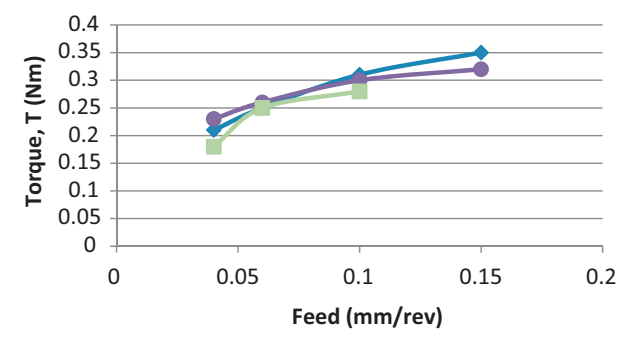

$\leadsto$ Torque $(\mathrm{Nm})-5000 \mathrm{rpm}$ $\rightarrow$ Torque (Nm) -7500 rpm - Torque (Nm) -10000 rpm

(b)

Fig. 7. Thrust force (a) and torque (b) measurements as a function of feed and speed for DCC-II.

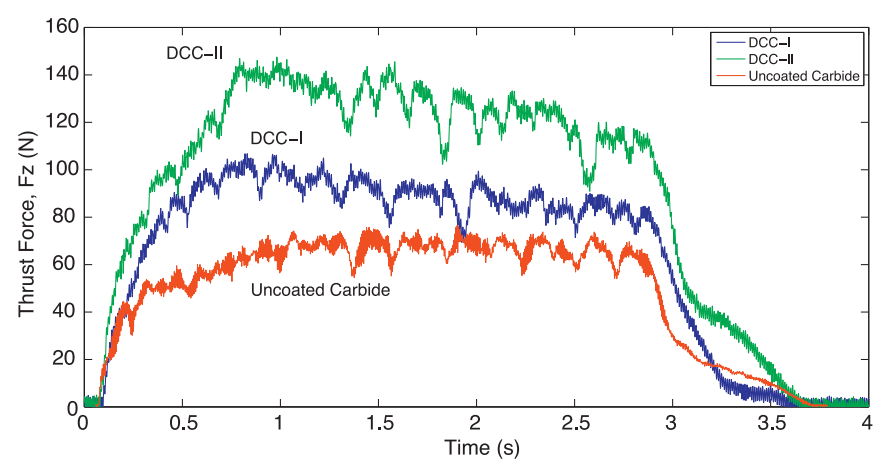

Fig. 8. Comparison of thrust forces for each drill at $N=5000 \mathrm{rpm}, f=40 \mu \mathrm{m} / \mathrm{rev}$.

a shorter secondary cutting edge. The force and torque measurements obtained for diamond coated carbide drills are investigated in detail in the next section.

\subsection{Influence of drill tip angles on drilling forces}

Fig. 9 shows the thrust forces acting on a double point angle drill and unchip thickness variation with respect to cutting edges. Thrust force measurements can be divided by two to calculate forces per edge. The total thrust force acting on the drill is the sum of thrust forces acting on three different sections. The thrust force in the primary region $(\mathrm{OA})$ is the sum of chisel edge force $\left(F_{\mathrm{ch}}\right)$ and primary edge force $\left(F_{\mathrm{pr}}\right)$. The thrust force in secondary region $\left(F_{\mathrm{sc}}\right)$ can be found by considering peak and entry thrust forces. Thrust forces in each section are represented in Eq. (1). The drill tip angles $\alpha$ and $\beta$ and the lengths of the primary and secondary edges are drill design variables. If the diameter of the drill and the height of the drill tip are known, the lengths of the primary and secondary regions can be calculated.

$\sum F_{z-\mathrm{OA}}=\frac{F_{z \text {-enter }}}{2}=F_{\mathrm{ch}}+F_{\mathrm{pr}}$

$\sum F_{z-\mathrm{AB}}=\frac{F_{z \text {-peak }}-F_{z \text {-enter }}}{2}=F_{\mathrm{SC}}$

The uncut chip thicknesses at primary and secondary cutting edges can be calculated as shown in Eq. (2), where $f$ is the feed per revolution. For a given feed, increasing tip angle increases uncut chip thickness in the respective area. Therefore, increasing tip angle

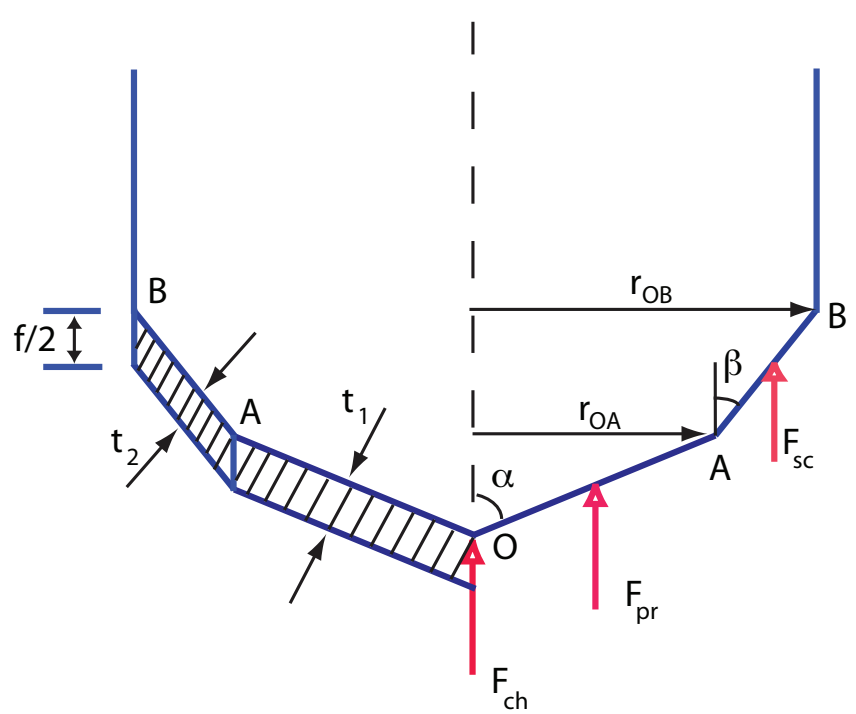

Fig. 9. Thrust forces acting on the drill (right hand side) and uncut chip thickness variation (left hand side). 


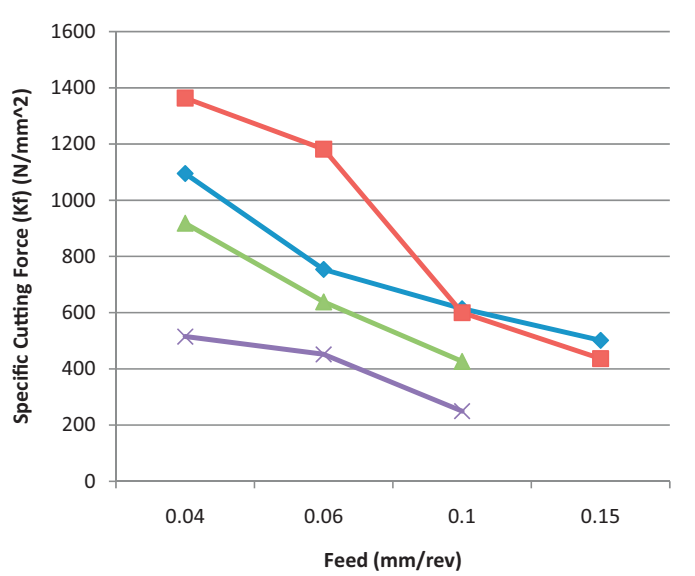

(a)

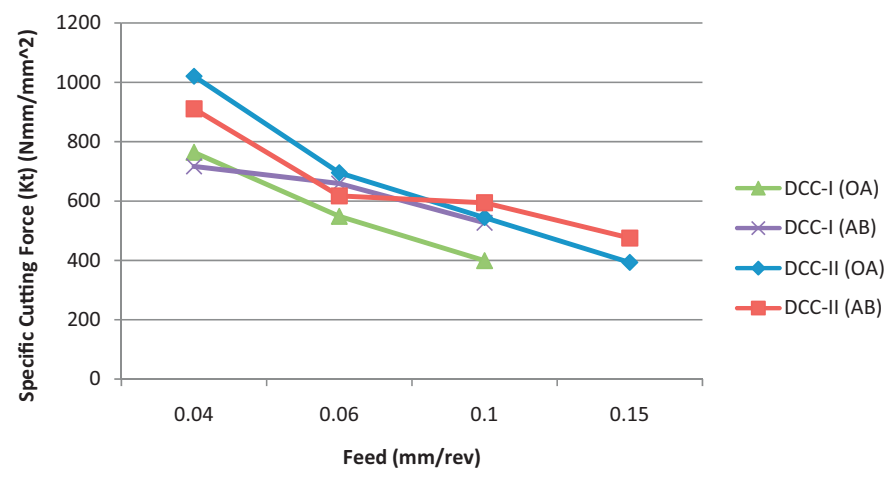

(b)

Fig. 10. Specific cutting forces calculated for (a) thrust force and (b) torque as a function of feed per revolution.

is usually accompanied by a decrease in the edge length in order to keep the total area same under the cutting edge.

$t_{1}=\left(\frac{f}{2}\right) \sin (\alpha), \quad t_{2}=\left(\frac{f}{2}\right) \sin (\beta)$

The area of the uncut chip underneath primary and secondary edges can be written as in Eq. (3).

$A_{\mathrm{OA}}=\frac{r_{\mathrm{OA}}}{\sin (\alpha)} t_{1}, \quad A_{\mathrm{AB}}=\frac{r_{\mathrm{OB}}-r_{\mathrm{OA}}}{\sin (\beta)} t_{2}$

Then Eq. (4) can be used to calculate the average specific cutting forces (related to thrust force and torque) separately for the primary and secondary cutting edges. Torque measurements are also divided by two to calculate per edge torque measurements.

$K_{f-p}=\frac{F_{z-\mathrm{OA}}}{A_{\mathrm{OA}}}, \quad K_{f-s}=\frac{F_{z-\mathrm{AB}}}{A_{\mathrm{AB}}}$

$K_{t-p}=\frac{T_{O A}}{\left(r_{\mathrm{OA}} / 2\right) A_{\mathrm{OA}}}, \quad K_{t-s}=\frac{T_{\mathrm{AB}}}{\left(\left(r_{\mathrm{OA}}+r_{\mathrm{OB}}\right) / 2\right) A_{\mathrm{AB}}}$

Fig. 10 shows average values of specific cutting forces calculated for DCC-I and DCC-II drills at $5000 \mathrm{rpm}$. A decreasing trend in cutting forces is observed with increrasing feed. This phenenomenon is known in machining as size effect. Cutting edge radius and work material properties are believed to be reasons for size effect.

Drilling performances of DCC-I and DCC-II geometries can be compared based on the specific cutting forces $\left(K_{f}\right.$ and $\left.K_{t}\right)$ calculated at the primary and secondary cutting edges. Under ideal drilling conditions for a given drill geometry, thrust force and torque must be distributed evenly between primary and secondary drilling edges. If the secondary cutting edge of the drill is designed to be small, then exit thurst forces will be small. However, at high

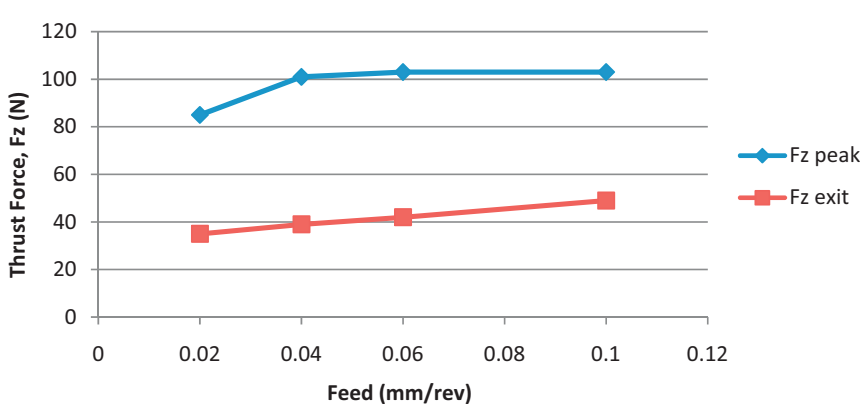

Fig. 11. Thrust forces measurements during drilling with a pilot hole $(N=5000 \mathrm{rpm})$.

feeds the torque carrying capability will decrease. In Fig. 10(a), it is seen that the primary edge of DCC-I carries more thrust load than the secondary edge due to its larger size. The torque load is carried equally at low feed level. As feed increases, torque is mainly carried on the secondary edge due to its shorter length as shown in Fig. 10(b). As for DCC-II, around $100 \mu \mathrm{m} / \mathrm{rev}$, it distributes the thrust force and torque almost evenly between primary and secondary edges (Fig. 10(a) and (b)). In general, cutting coefficients are smaller for DCC-I due to smaller tip angle, therefore DCC-I may be a better option for drilling thin CFRP laminates, where low feeds are usually used to keep thrust forces low. DCC-II geometry can be employed in drilling thick laminates at higher feeds. The mechanical properties of the CFRP laminates depend on many factors, including carbon

a

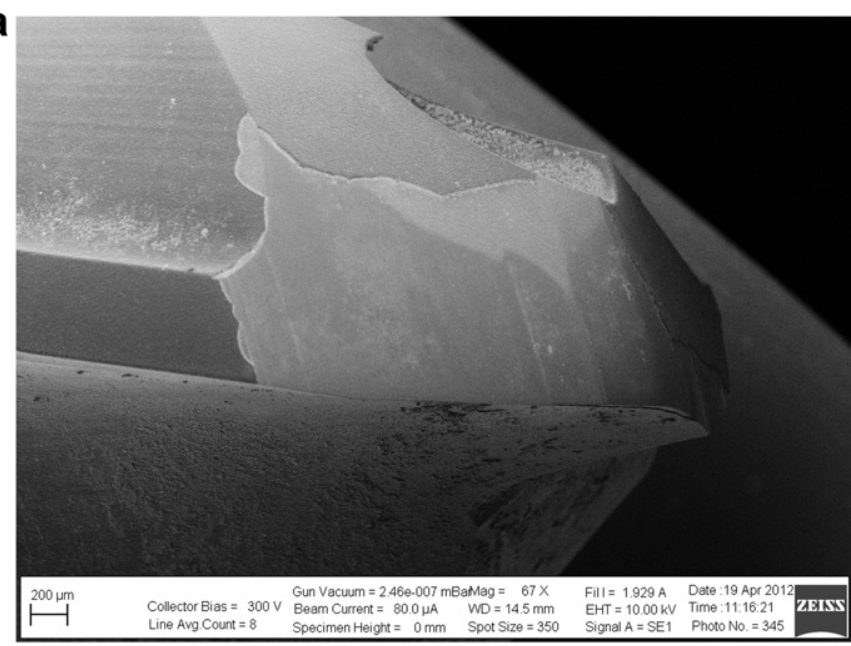

b

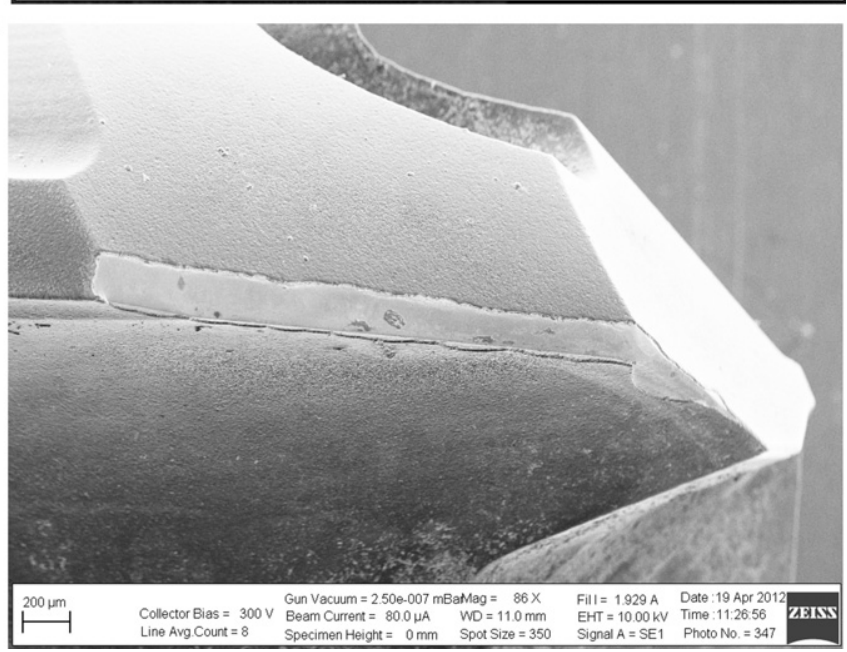

Fig. 12. SEM images of DCC-II drills (a) $N=10,000 \mathrm{rpm}, f=40 \mu \mathrm{m} / \mathrm{rev}$ and (b) $N=10,000 \mathrm{rpm}, f=100 \mu \mathrm{m} / \mathrm{rev}$ (after drilling 1728 holes). 
a

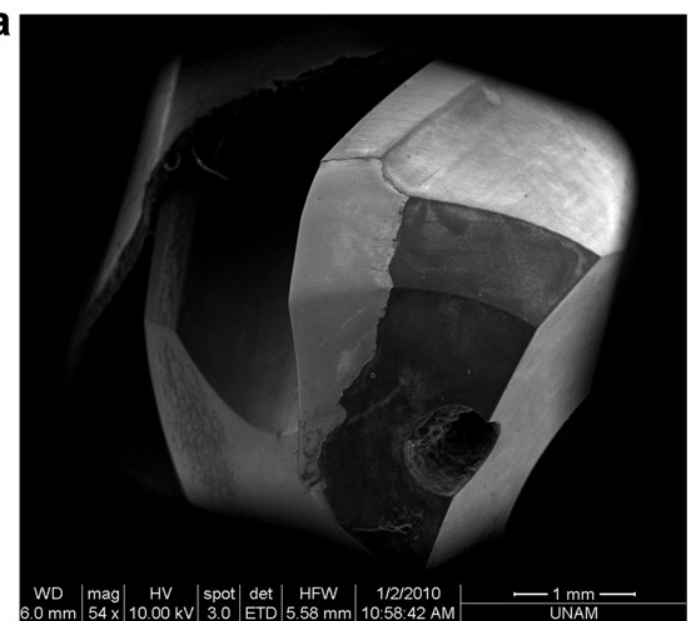

C

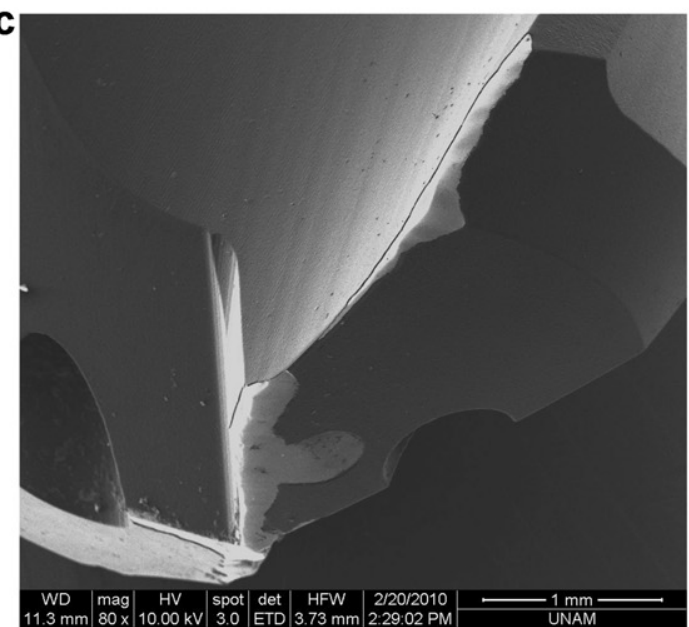

b

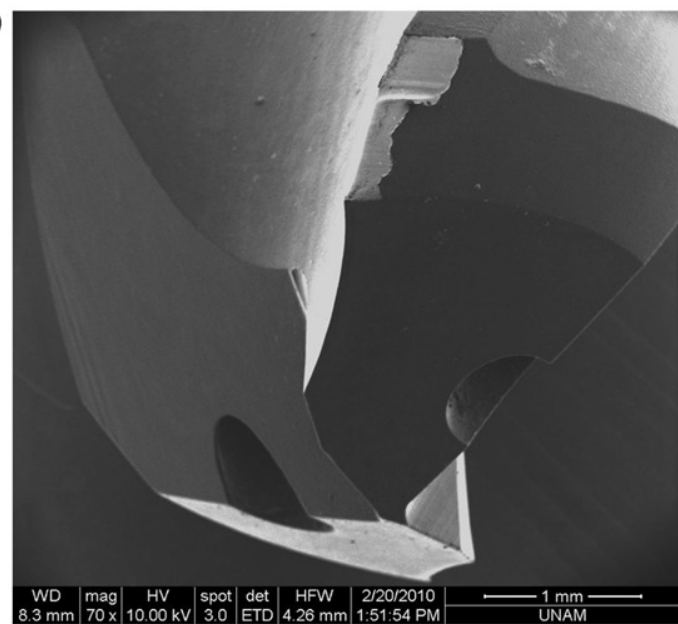

d

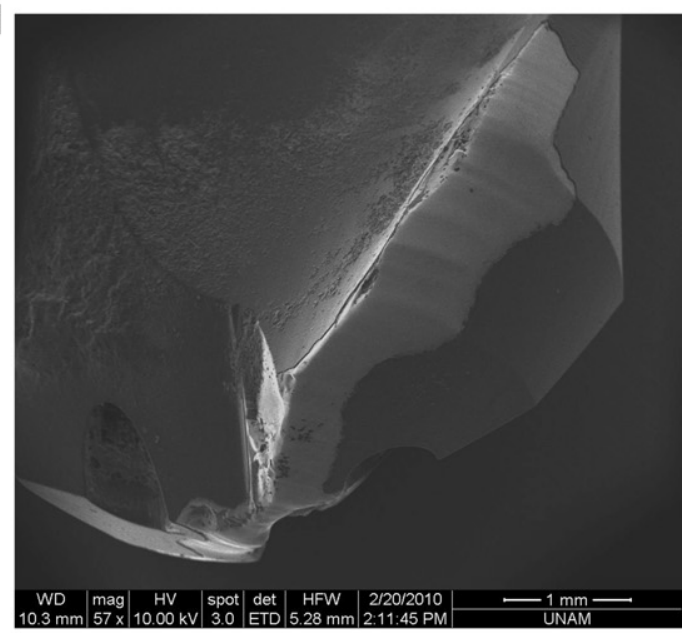

e
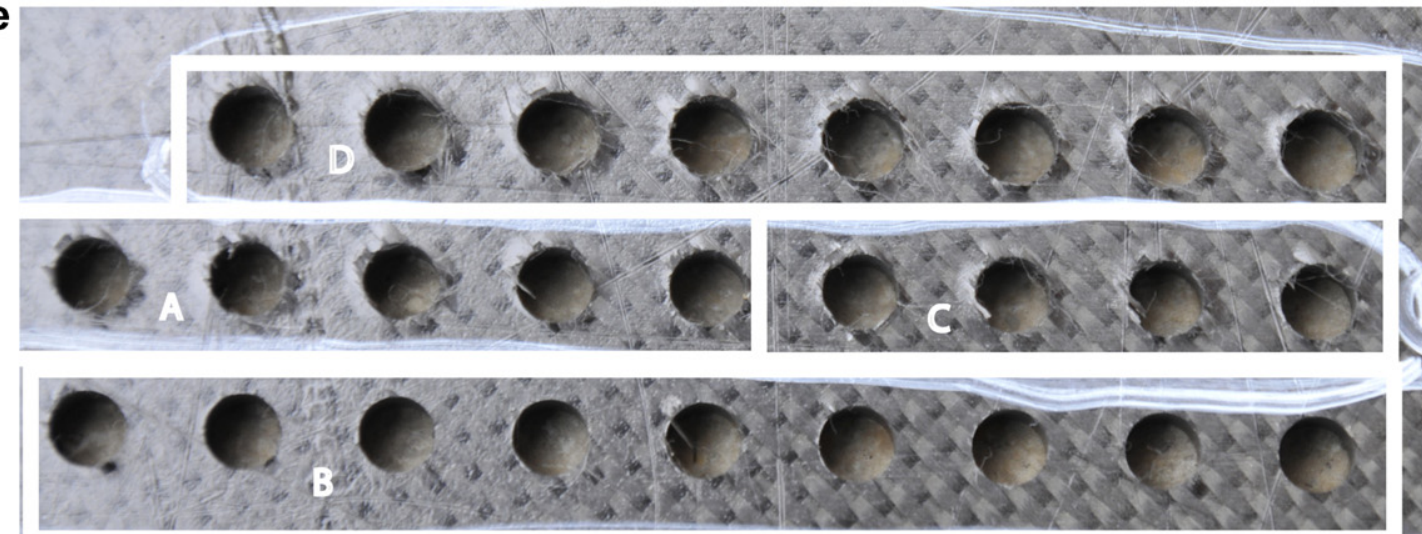

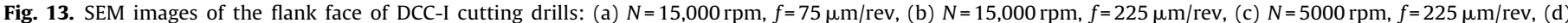
$N=5000 \mathrm{rpm}, f=75 \mu \mathrm{m} / \mathrm{rev}$ and (e) hole exits correspond to each experimental condition.

fiber percentage, carbon fiber diameter, type of resin used in the matrix, curing conditions, etc. Developing an optimized drill geometry which will perform well at all composite materials may not be possible, as explained above, but determining favorable drilling conditions for a given drill geometry or selecting drill geometry based on laminate thickness is possible.

In order to investigate the influence of the tip of the drill on the thrust forces, drilling experiments were also conducted on predrilled holes of $2.5 \mathrm{~mm}$. Thrust force measurements are shown in Fig. 11. The diameter of the pilot hole is selected so that it matches the size of the region $\mathrm{OA}^{\prime}$ (see Fig. 3). Peak forces become stationary after the feed value of $40 \mu \mathrm{m} / \mathrm{rev}$ while exit thrust force continues increasing at a lower rate than it does when drilling without a predrilled hole. The contribution of the region $\mathrm{OA}^{\prime}$ on the thrust force measurements can be calculated as $50 \%$ based on measurements given in Figs. 7 and 11.

It must be noted that the chip formation process in CFRP laminates consists of shearing and brittle fracturing of the fibers. As feed increases, due to larger loads, fibers are crushed more easily and dominant chip formation mechanism becomes the brittle 

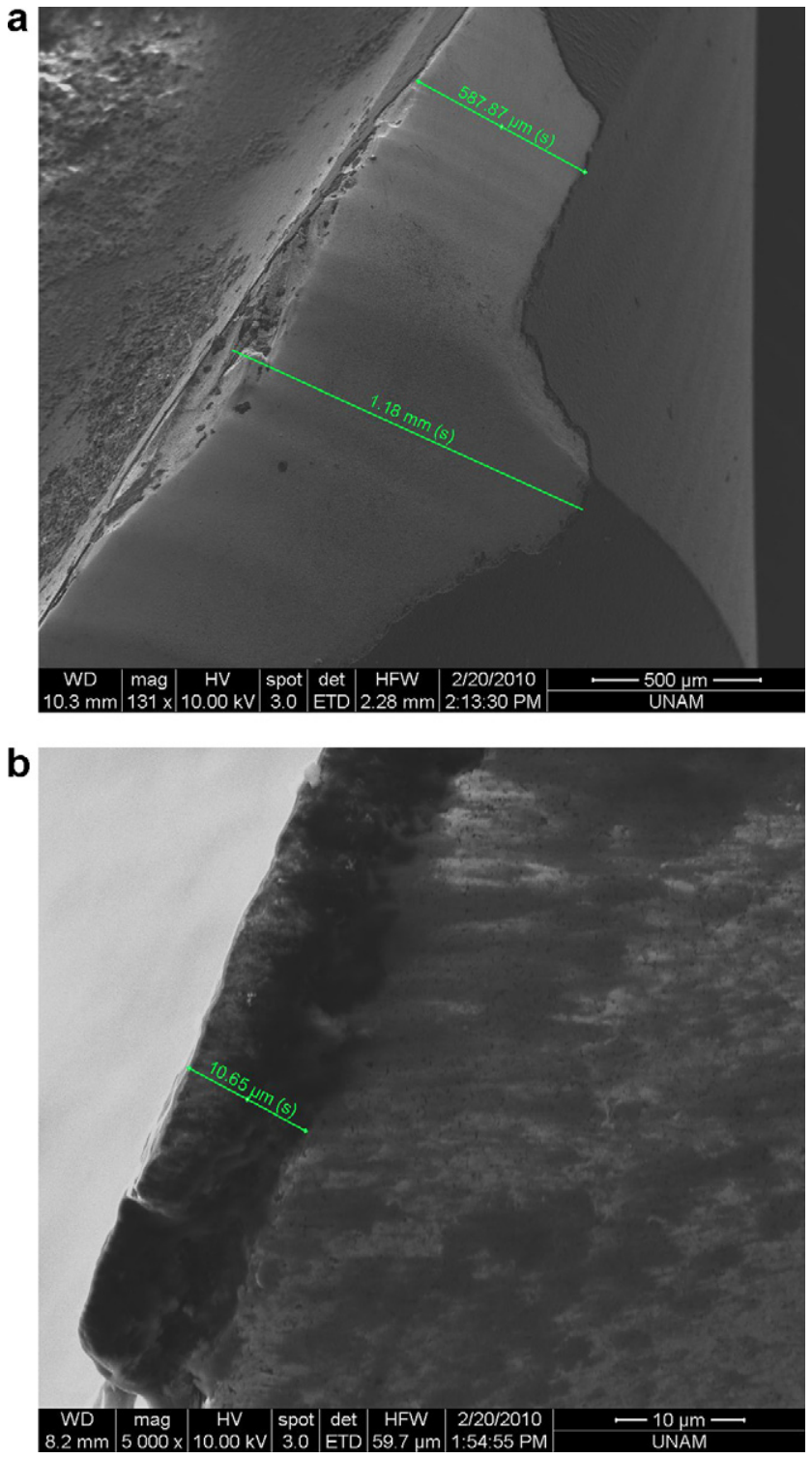

Fig. 14. SEM images of the fractured diamond coating zone.

fracturing of the fibers. This may explain plateau in cutting forces with increasing feed as shown in Fig. 11.

\section{Investigating the relationships between drill wear and drilling operational parameters}

Diamond coated carbide and uncoated carbide drills are used in this study. Diamond coating is grown on the surface of the cutting drill through chemical vapor deposition, where hydrogen and a gas containing carbon are mixed inside a chamber at very high temperatures. The thickness of the coating and the size of the diamond particles are known to be important in terms of drill performance. Diamond coating can be applied to a wide range of drill geometries; however, the coating's thickness decreases the sharpness of the cutting drill edge, which is not desirable when machining CFRP laminates. This section investigates the condition of the diamond coating on the drill as a function of drilling parameters. Fig. 12(a) and 12(b) shows the photos of the DCC-II drill after drilling 1728 holes at 40 and $100 \mu \mathrm{m} / \mathrm{rev}$ at $10,000 \mathrm{rpm}$, respectively. Diamond coating on the drill is observed to be damaged in both drilling cases. Low feed drilling case (Fig. 12(a)) resulted in more severe damage

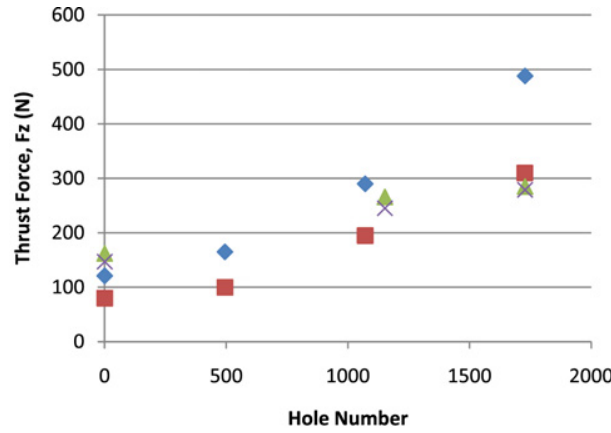

$\checkmark F z$ peak $(0.04 \mathrm{~mm} / \mathrm{rev})$

Ez int $(0.04 \mathrm{~mm} / \mathrm{rev})$

$\triangle \mathrm{Fz}$ peak $(0.1 \mathrm{~mm} / \mathrm{rev})$

$\times F z$ int $(0.1 \mathrm{~mm} / \mathrm{rev})$

(a)

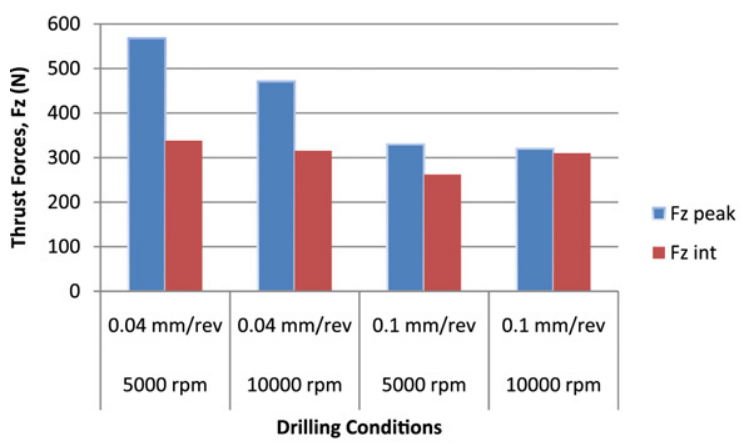

(b)

Fig. 15. (a) Force variation in DCC-II drill with respect to number of holes and (b) worn drill thrust forces with respect to drilling parameters.

to the drill. The diamond coating is mostly fractured from the flank face of the drill, and the fractured area is larger in the secondary region. Fig. 12(b) shows that in high feed drilling case, fracture on the coating initiates from the secondary region and grows toward the primary region. At low feed drilling case, the total distance the drill travels within the hole is 2.5 times larger than the high feed case. When the diamond coating is fractured, thrust forces and torques increase. As a result, the bottom plies of the laminate are pushed out by larger thrust forces, and eventually delamination occurs.

In order to investigate the influence of larger feed rates on drilling performance, tests are performed with DCC-I drills under a larger speed and feed experimental range $(5000-15000 \mathrm{rpm}$ and 75-225 $\mu \mathrm{m} / \mathrm{rev})$. Fig. 13 reveals the wear zone at the flank face of the drills after drilling 1728 holes.

Similarly, fracture of the diamond coating is more severe on the flank face than the rake face of the drill. The smallest fracture area on the diamond coating on the flank face was observed in the experimental case of $N=15,000 \mathrm{rpm}, f=225 \mu \mathrm{m} / \mathrm{rev}$ (Experiment B) where a large feed was taken at high cutting speed (Fig. 13(b)). Diamond coating on the drill was significantly fractured at the outer edge of the cutting edge, possibly due to high torque, for there was no significant delamination at the exit of the holes as shown in Fig. 13(e). Coating on the primary cutting edge and chisel edge of the drill is intact. The experimental case with the lowest feed rate (Experiment $\mathrm{D}$ ) yielded the worst experimental performance in terms of diamond coating fracture zone area and resulted in problems at the exit of the hole due to excessive edge rounding and ineffective cutting performance as shown in Fig. 13(e). High feed and low speed drilling case (Fig. 13(c)) yielded a smaller fractured area of the diamond coating compared to low feed and high speed drilling case (Fig. 13(a)). Fig. 14 shows detailed SEM images of the fractured coating zone that correspond to experimental case (D) shown in Fig. 13. The thickness of the diamond coating is measured to be $9-10 \mu \mathrm{m}$. 


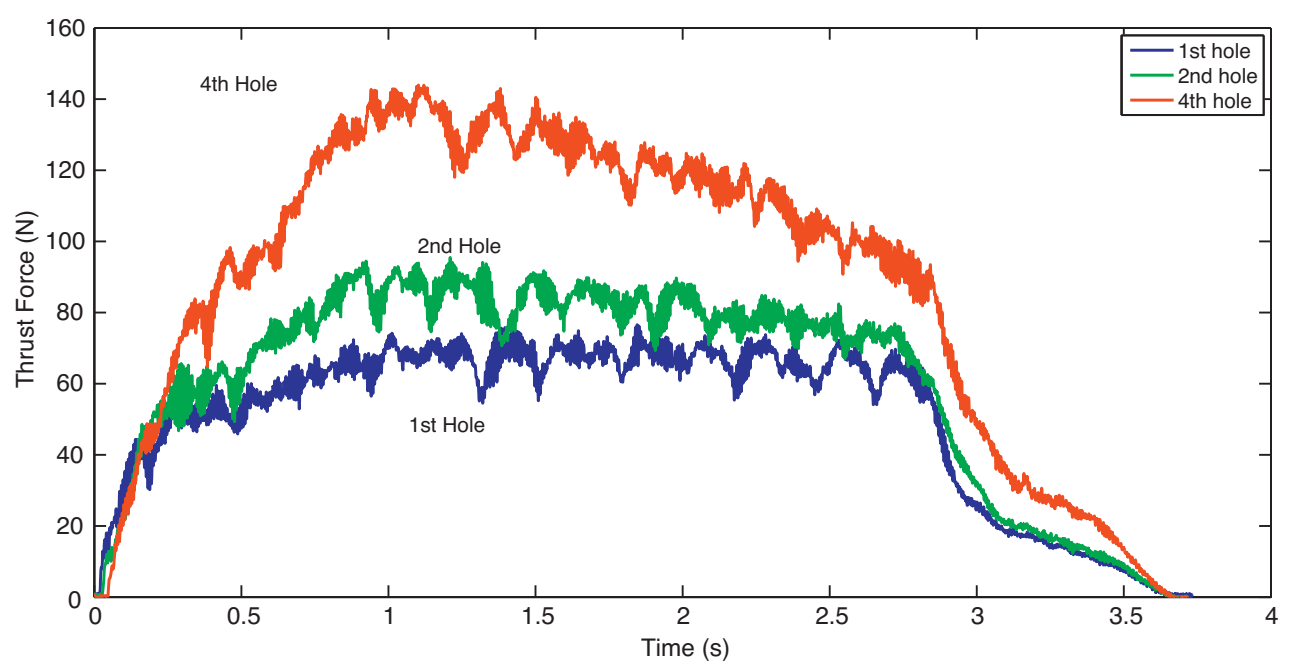

(a)

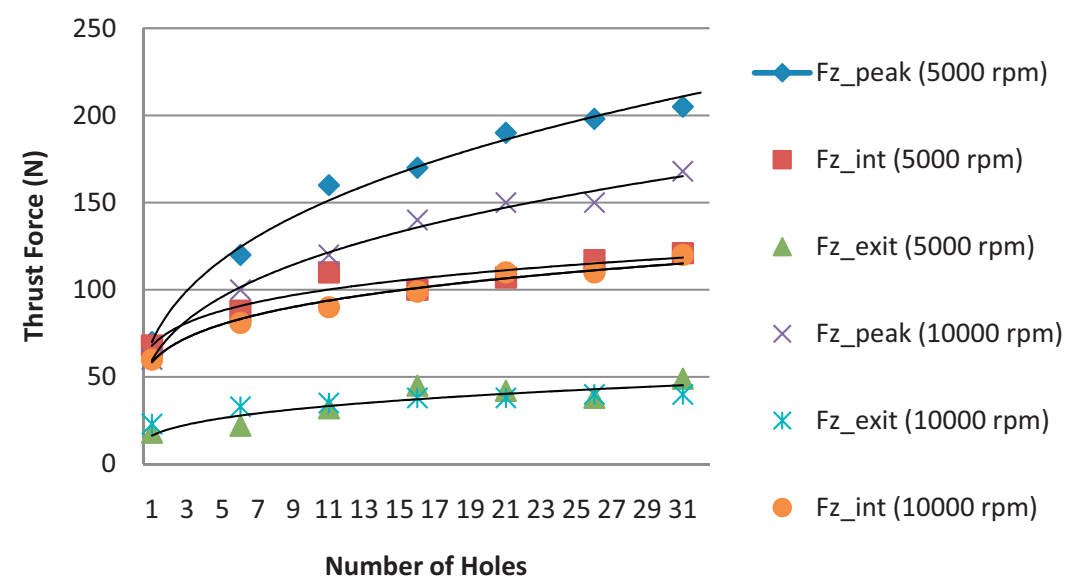

(b)

Fig. 16. (a) Time history of thrust force measurements as a function of number of holes and (b) influence of rotational speed on thrust forces (at $f=40 \mu \mathrm{m} / \mathrm{rev}$ ).

Fig. 15(a) shows the variation in thrust forces with respect to the number of drilled holes for DCC-II after drilling 1728 holes at two different feeds with constant rotational speed of $10,000 \mathrm{rpm}$. Forces increase according to power law and continue increasing linearly. For the same number of holes, high feed drilling case resulted in lower thrust forces than in the low feed drilling case. Consequently, drilling at low feed initially results in lower exit forces, but due to faster drill wear, thrust forces become even larger after drilling the same number of holes. Fig. 15(b) represents the comparison of thrust forces measured after drilling 1728 holes under different drilling conditions. The positive influence of high speed and feed can be seen. The differences between high and low speed when drilling at a high feed are not large. At $5000 \mathrm{rpm}$ and $75 \mu \mathrm{m} / \mathrm{rev}$ feed drilling condition with DCC-I drill, peak thrust force was measured as $1553 \mathrm{~N}$ after drilling 1728 holes.

Fig. 16(a) represents experimental force measurements when drilling with uncoated carbide cutting drills. After drilling only four holes, its thrust force value surpasses that of the DCC-II with the same drill geometry. The rate of increase in peak thrust forces is quite high, indicating rapid drill wear especially at the primary region of the drill $\left(F_{z \text {-enter }}\right.$ and $\left.F_{z \text {-peak }}\right)$. The increase in exit thrust force is relatively low compared to other characteristic thrust force points, indicating a lower wear rate at the secondary cutting edge. Fig. 16(b) shows the influence of speed on drilling forces, where the variation of characteristic thrust force points is shown with respect to number holes at constant feed. A power law equation can be used to represent the relationship between thrust force and number of holes for the uncoated carbide drill. Based on hole exit quality for uncoated carbide drills at $5000 \mathrm{rpm}$ and $40 \mu \mathrm{m} / \mathrm{rev}$ the acceptable drill life was observed to be 20 holes, around which the exit thrust force was $50 \mathrm{~N}$ (Fig. 16(b)). This thrust force value $\left(F_{z \text {-int }}\right)$ is named as the critical thrust force value.

In order to determine drill life, hole exits are usually inspected for delamination. Some visual techniques have been proposed in the literature in order to decide whether imperfections at the hole exit have reached an unacceptable level. These techniques measure the diameter of the delaminated area using a camera and calculate an index relative to nominal hole diameter (Schulze et al., 2010). Inspection of delamination requires a detailed examination of the holes and also removal of the CFRP laminate from the fixture in order to check hole exits. On the other hand, hole diameters can easily be controlled during production by using gauges or micrometers. In order to investigate the influence of high feeds on hole quality, hole diameters are automatically measured using a coordinate measurement machine (DEA-Delta Slant) every 96 holes. Fig. 17 shows the diameter measurement variations for different drilling conditions. The decrease in diameter is acceptable as long as it stays within specified tolerances defined by the manufacturer. A decreasing trend in hole diameters with respect to the number of drilled holes is clearly observed. The lower limit of acceptable hole diameter is assumed to be $6.35 \mathrm{~mm}$ where DCC-II drill with 


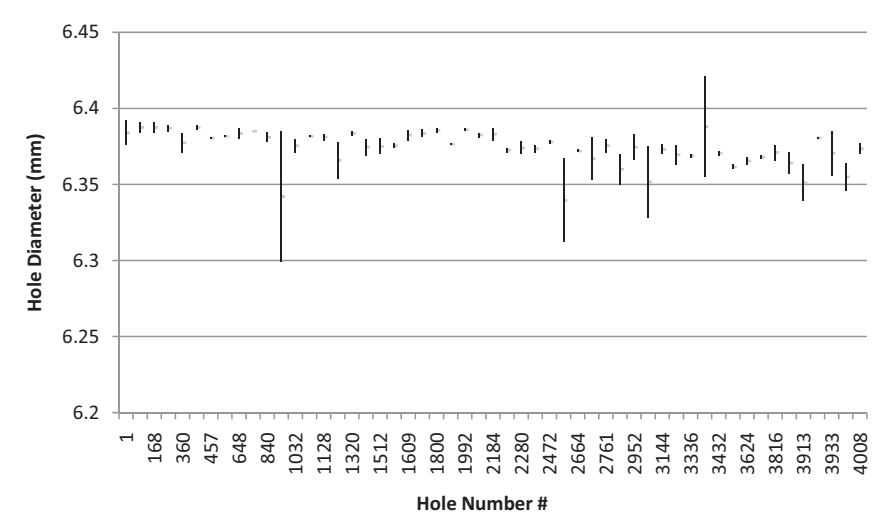

(a)

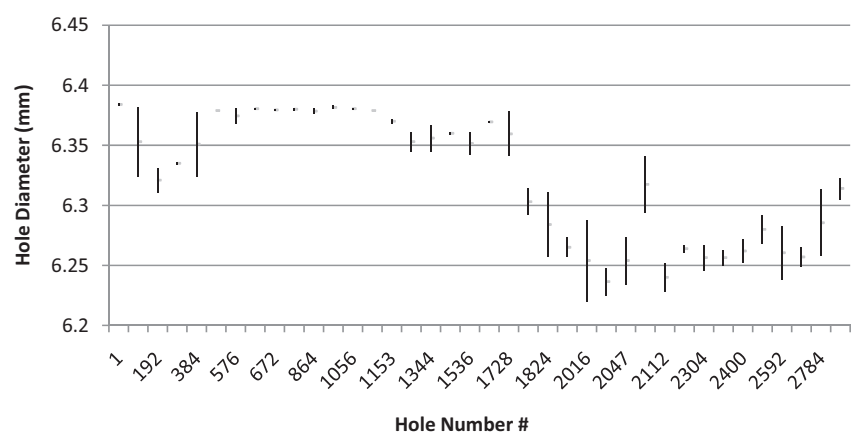

(b)

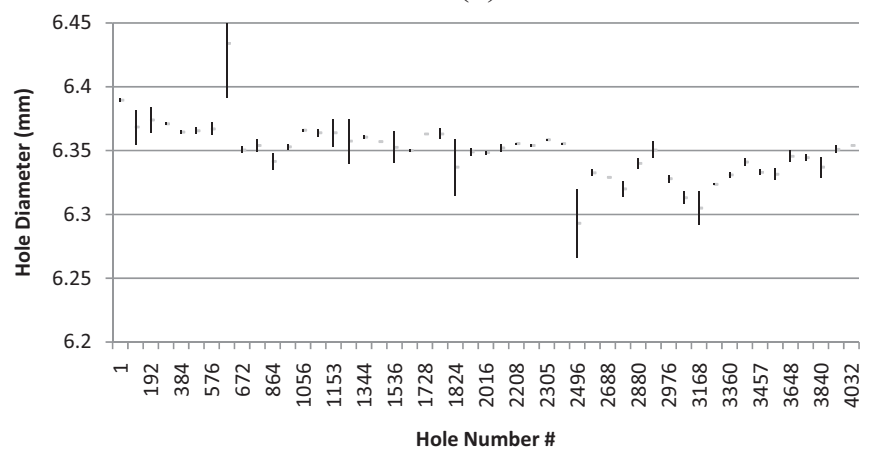

(c)

Fig. 17. Variation of diameter with respect to hole number: (a) $N=15,000 \mathrm{rpm}$, $f=225 \mu \mathrm{m} / \mathrm{rev}$, (b) $N=5000 \mathrm{rpm}, f=225 \mu \mathrm{m} / \mathrm{rev}$ and (c) $N=15,000 \mathrm{rpm}$, $f=300 \mu \mathrm{m} / \mathrm{rev}$ (DCC-II drill with $6.38 \mathrm{~mm}$ diameter).

$6.38 \mathrm{~mm}$ nominal diameters are used in experiments. Hole diameter variation measurements reveal that high feed and speed drilling conditions $(N=15,000 \mathrm{rpm}, f=225 \mu \mathrm{m} / \mathrm{rev})$ reach the lower tolerance level of $6.35 \mathrm{~mm}$ around 4000 holes as shown in Fig. 17(a). No delamination problem was observed at the hole exits. When speed is reduced to $5000 \mathrm{rpm}$, hole diameter tolerance is also reached around 1700 holes (Fig. 17(b)). The influence of faster drill wear at low feed is observed on hole diameters. When feed is increased to $300 \mu \mathrm{m} / \mathrm{rev}$ at $15,000 \mathrm{rpm}$, a large scatter on measured diameters was observed. Tolerance level was reached within 1700 holes as shown in Fig. 17(c).

Based on the findings given above, increasing feed and rotational speed helps protect diamond coating on the drill, which in turn results in better drill performance in terms of hole quality. The results presented in this study do not agree with majority of the results reported in the literature, where low feed and high speed drilling are recommended in terms of delamination based hole quality criteria. It must be noted that the properties of CFRP material, drilling geometry, and rigidity of the machine tool all play an important role in these observations. The rigidity of the machine tool is known to influence drilling stability, drill life, and hole quality. Increasing thrust force with increasing feed may result in vibrations during drilling, which adversely affect process outputs. While Fig. 2 may give an idea about the rigidity of the machine tool used in this study, an impact hammer test was performed to measure its dynamic properties. The results were obtained through CutPro $^{\mathrm{TM}}$ software and the spindle-tool holder-drill system is measured to have a natural frequency of $3500 \mathrm{~Hz}$, stiffness of $1 \mathrm{e} 9 \mathrm{~N} / \mathrm{m}$, and a damping ratio of $1.846 \%$ (equal in $x$ and $y$ directions).

In the literature, the positive impact of using backing plates while drilling CFRP laminates has been reported especially when drilling unidirectional type CFRP laminates. In this study, tests are repeated without using a backing plate, and no significant differences were observed in terms of measured drilling forces or hole quality. Fabric woven laminates are more resistant to delamination than unidirectional CFRP laminates. Therefore, during production of unidirectional CFRP laminates, fabric woven CFRPs are usually used at the top and bottom of the laminates to decrease the likelihood of delamination during drilling operations. A recent trend in aerospace manufacturing requires CFRP laminates to be drilled together with titanium/aluminum alloy plates as stacks in order to make assembly operations easier. Drill geometry selection and/or design becomes more challenging due to different material properties.

\section{Conclusions}

This study examines drilling of fabric woven CFRP laminates and observes the performance of drill geometry as a function of drilling operational parameters. The experimental study was conducted under industrial conditions using specialized equipment for CFRP machining.

- The interplay among the exit thrust force, the torque carrying capability of the secondary edge, and the load distribution between the primary and secondary edges is presented as a function of drill angles and edge lengths.

- Delamination in fabric woven CFRP laminates is observed to be closely associated with the condition of the diamond coating. Peak thrust forces are observed to increase significantly as a result of fracturing of the diamond coating.

- DCC-II drill geometry is found to be more suitable to high feed drilling than DCC-I geometry.

- Hole diameter tolerance is observed to be more critical than delamination during the drilling experiments conducted in this study.

\section{Acknowledgements}

The authors would like to thank The Scientific and Technical Research Council of Turkey (TUBITAK-Teydeb) and ODAGEM A.S. for their financial support of this study.

\section{References}

Abrao, A.M., Faria, P.E., Campos Rubio, J.C., Reis, P., Davim, P., 2007. Drilling of fiber reinforced plastics. A review. Journal of Materials Processing Technology 186, $1-7$.

Caprino, G., Santo, L., Nele, L., 1998. Interpretation of size effect in orthogonal machining of composite materials. Part I: unidirectional glass fibre reinforced plastics. Composites Part A 29A, 887-892.

Chen, W.C., 1997. Some experimental investigations in the drilling of carbon fiber reinforced plastic (CFRP) composite laminates. International Machine Tools \& Manufacture 37, 1097-1108.

Dharan, C.H.K., Won, M.S., 2000. Machining parameters for an intelligent machining system for composite laminates. International Machine Tools \& Manufacture 40, 415-426. 
Faraz, A., Biermann, D., Weinert, K., 2009. Cutting edge rounding: an innovative drill wear criterion in drilling CFRP composite laminates. International Machine Tools \& Manufacture 49, 1185-1196.

Hocheng, H., Dharan, C.H.K., 1990. Delamination during drilling in composite laminates. Journal of Engineering for Industry 112, 236-239.

Hocheng, H., Tsao, C.C., 2005. The path towards delamination-free drilling of composite materials. Journal of Materials Processing Technology 167, 251-264.

Iliescu, D., Gehin, D., Gutierrez, M.E., Girot, F., 2010. Modeling and drill wear in drilling of CFRP. International Machine Tools \& Manufacture 50, 204-213.

International Air Transport Association (IATA) Fact Sheet:Fuel, 2012. http://www.iata.org/pressroom/facts_figures/fact_sheets/pages/fuel.aspx.

Karpat, Y., Camuscu, N., Kılıç, A., Sonat, F., Değer, B., Bahtiyar, O., 2010. Drilling carbon fiber reinforced plastics with diamond coated carbide cutting drills. In: Proceedings of the 36th International Matador Conference, Manchester, UK, pp. 205-208.

Koplev, A., Lystrup, A., Vorm, T., 1983. The cutting process, chips and cutting forces in machining CFRP. Composites 14, 371-376.

Lazar, M.B., Xirouchakis, P., 2011. Experimental analysis of drilling fiber reinforced composites. International Machine Tools \& Manufacture 51 (12), 937-946.
Piquet, R., Ferret, B., Lachaud, F., Swider, P., 2000. Experimental analysis of drilling damage in thin carbon/epoxy plate using special drills. Composites Part A: Applied Science and Manufacturing 31, 1107-1115.

Rawat, S., Attia, H., 2009. Characterization of the dry high speed drilling process of woven composites using machinability maps approach. CIRP Annals - Manufacturing Technology 58, 105-108.

Schulze, V., Becke, C., Weidenmann, K., Dietrich, S., 2010. Machining strategies for hole making in composites with minimal workpiece damage by directing the process forces inwards. Journal of Materials Processing Technology 211 (3), 329-338.

Shyha, I.S., Aspinwall, D.K., Soo, S.L., Bradley, S., 2009. Drill geometry and operating effects when cutting small diameter holes in CFRP. International Machine Tools \& Manufacture 49, 1008-1014.

Teti, R., 2002. Machining of composite materials. CIRP Annals - Manufacturing Technology 51, 611-634.

Tsao, C.C., Hocheng, H., 2005. Effects of exit back-up on delamination in drilling composite materials using a saw drill and a core drill. International Journal of Machine Drills \& Manufacture 45, 1261-1270.

Zhang, L.B., Wang, L.J., Liu, X.Y., 2001. A mechanical model for predicting critical thrust forces in drilling composite laminates. Proceedings of the Institution of Mechanical Engineers 215, 398-405. 